\title{
A Preliminary Study of Diet, Overweight, Elevated Blood Pressure, and Acanthosis Nigricans Among K-9th Grade Native American Students
}

\author{
Cindy Wolff, Sabrina Hoang, Diana Flannery, Laurie Wermuth \\ California State University, Chico
}

\begin{abstract}
Childhood overweight is associated with increased rates of hypertension (HTN) and acanthosis nigricans (AN), a known risk factor for diabetes. This cross-sectional study of predominantly Native American students examined relationships between diet and overweight, AN, and HTN among K-9th grade students. Eighty-six students completed a questionnaire regarding fruit and vegetable $(\mathrm{F} / \mathrm{V})$ consumption and physical activity (PA) behaviors. Anthropometric data, blood pressure (BP), and presence of AN were determined by trained screeners. Fifty-three percent of the Native American study participants were overweight or at-risk-for-overweight (BMI $\geq 85$ th percentile), while $35 \%$ of the non-Native American participants were overweight or at risk for overweight. At $60 \%$ vs. $35 \%$ respectively, the percentage of students either overweight or at risk for overweight was significantly higher $(p=.02)$ among fourth through ninth graders compared with students in kindergarten through third grades. Fourteen percent were positive for AN, and 33\% had either Pre-HTN or HTN ( $\geq 90$ th percentile) based on the first blood pressure reading. Analysis of variance results indicated that students with either pre-HTN or HTN had a significantly higher mean BMI $(24.1 \pm 8.0)$ vs. those with normal BP $(20.4 \pm 5.1 ; \mathrm{P}=.012)$. BMI was positively correlated with $\mathrm{AN}(\mathrm{r}=0.433, \mathrm{p}=.01)$ such that all students positive for $\mathrm{AN}$ had a BMI $\geq 85$ th percentile $(\mathrm{p}=.001)$. Students who agreed with the Likert statement that they usually eat $\geq 5 \mathrm{~F} / \mathrm{V}$ a day had a significantly lower mean systolic BP $(107 \mathrm{mmHg} \pm 17)$ vs. those who did not $(123 \mathrm{mmHg} \pm 17, \mathrm{P}=.001)$. Regression results indicate that BMI and attitude toward the importance of fruit and vegetable consumption are independent predictors of systolic BP $(p=.001)$. Results suggest that significant numbers of students in this sample are positive for AN, are overweight, and are at risk for hypertension and that more positive attitudes toward fruit and vegetable consumption are associated with lower blood pressure levels. Prevention programs to address these health problems are discussed.
\end{abstract}

(C) 2006 Californian Journal of Health Promotion. All rights reserved.

Keywords: Overweight, diet, blood pressure, Native Americans

\section{Introduction and Background}

The rate of overweight among youth is steadily increasing. According to the National Institutes of Health (NIH, 2002), the number of children who are overweight has doubled in the last two to three decades; currently one child in five is overweight. The prevalence of overweight among children increased from $5 \%$ to $11 \%$ from the $1960 \mathrm{~s}$ to the 1990s (Freedman, Dietz, Srinivansan \& Berenson, 1999). NIH (2006) warns, "A large number of studies have found that obesity persists from childhood through adolescence and into adulthood. Obese adolescents are likely to become overweight adults and, as such, at risk for the complications of obesity-cardiovascular disease, high blood pressure, stroke, and diabetes." The National Institute of Child and Human Development's Study of Early Child Care and Youth Development (NIH, 2006; $n=1,000)$ found that when compared to children who were not overweight, children who became overweight during two different time periods during the elementary school period were 159 times more likely to be overweight at 12 years old. Children overweight three times during elementary school were 374 times more likely to be overweight at 12 (Nader et al., 2006; NIH, 2006). Preschool and elementary age children in the NICHD study with BMIs between the 50th and 75th percentile 
had significantly higher rates of overweight when they reached age 12 (NIH, 2006). Health outcomes related to childhood overweight also include acanthosis nigricans (AN) and psychosocial problems (Sorof \& Daniels, 2002). Because childhood overweight frequently persists into adulthood and is a risk factor for major diseases, early detection and treatment is imperative for disease prevention.

\section{Overweight}

At-Risk-for-Overweight and

Among children and youth, there is no firm definition for obesity. Rather, the terms at-riskfor-overweight and overweight are used. The definition of at-risk-for-overweight is defined as a BMI value greater than or equal to the 85 th percentile but less than the 95th percentile of BMI for age. Children with a BMI greater than or equal to the 95th percentile are identified as overweight (St. Onge, Keller \& Hewymsfield, 2003).

Patrick and colleagues (2004) found that significantly more than half of overweight 10 to 13 year old children grow up to be overweight or obese adults. In addition, adolescent overweight increases the risk of adult morbidity from type 2 diabetes, heart disease, hypertension, and more (Smith \& Rinderknecht, 2003).

There is a higher rate of overweight among American Indians compared to US averages (Burke, Beilin, Dunbar \& Kevan, 2004; Gray \& Smith, 2003; Stoddart, Blevins, Lee, Wang \& Blackett, 2002; Story et al., 2003). The rate of overweight among American Indians is two to three times that of the general population for the same age and the rate continues to climb (Gray et al., 2003; Story et al., 2003). In a study of 12,560 American Indian children ages 5 to 17, $61 \%$ of boys and $56 \%$ of girls were either atrisk-for-overweight or overweight (Story et al., 2003). In a second study of 155 American Indian youth ages 5 to 18, Smith and Rinderknecht (2003), found that $22 \%$ were at-risk-foroverweight and an additional $41 \%$ were overweight for a total of $63 \%$ above the 85 th\%tile. These high rates of overweight may be attributed, in part, to excessive consumption of butter, lard, whole milk, fried foods, sugared beverages, and heavy use of oil in American Indian cooking. Overweight Native American adolescents have been found to have a greater preference for high-fat foods and sweetened and carbonated beverages compared to leaner adolescents (Story, Strauss, Zeprhier \& Broussard, 1998).

Rates of weight related risk factors are increasing among American Indian youth (Stoddart et al., 2002; Story et al., 1998). Type 2 diabetes has previously been considered rare among children, but over the last fifteen years, there has been a steady increase in the rate of diagnosis (Arslanian, 2000). American Indian children have a higher rate of this disease than do children of other ethnicities (Gahagan \& Silverstein, 2003).

In addition to type 2 diabetes, overweight children and adolescents are more likely to have elevated blood pressure (Freedman et al., 1999; Smith \& Rinderknecht, 2003; Sorof, 2004). Overweight American Indian youth have been shown to have higher rates of high blood pressure than their lean counterparts (Smith \& Rinderknecht, 2003). Sorof (2004) found that among ethnically diverse school age children, the prevalence of hypertension was $19.4 \%$, $9.5 \%$, and $4.5 \%$, respectively, for the first, second, and third screenings. The prevalence of hypertension increased progressively as the BMI percentile increased from normal weight $(2 \%)$ to overweight (11\%) categories (Sorof, 2004). High blood pressure is a common risk factor for chronic disease that may track from childhood to adult life (Steinberger, Daniels et al., 2003). Twenty-six percent of American Indian adults have been diagnosed with high blood pressure, exceeding the rate of the general population (Bursac \& Campbell, 2003).

\section{Acanthosis Nigricans}

Acanthosis nigricans (AN) is associated with type 2 diabetes and is characterized by darkened, coarse and hyperkeratinized skin cells commonly found around the neck, axillary, and groin regions. AN is a general indicator of insulin resistance at the cellular level and its presence is indicative of an increased risk for type 2 diabetes (Stoddart et al., 2002). The 
presence of extra insulin circulating in the blood stream stimulates insulin-like growth factor receptors that cause skin cells on the surface layer to proliferate (Scheinfield, 2004). Among American Indians, the affected skin is typically more pigmented and may appear discolored. AN is now common in younger individuals, especially in groups with high rates of adult diabetes. Among overweight children, AN is most prevalent in American Indian, African American, and Hispanic ethnicities (Story et al., 1999).

As with the prevalence of overweight, the rate of AN and hyperinsulinemia increases with age, particularly after age 10 (Stoddart et al., 2002; Stuart, Smith, Gilkison, Shaheb \& Stahn, 1994). Stuart and colleagues found a prevalence of $19 \%$ of AN among 1,141 American Indian children 319 years old (Stuart, 1994). Among the 2,005 participants in the Cherokee Diabetes Study, Stoddart and colleagues (2002) found the prevalence rates of $\mathrm{AN}$ and hyperinsulinemia to be $34 \%$ and $42 \%$, respectively. Fasting insulin concentrations were two times higher in participants with AN than in weight-matched subjects without AN. Researchers have found that the occurrence of AN was between $56 \%$ and 92\% among overweight Japanese children with type 2 diabetes (Yamazaki, Ito \& Hoshida, 2003).

\section{Fruits and Vegetables}

Consuming the recommended daily servings of fruits and vegetables has been reported to decrease the risk in heart disease and cancer (US General Accounting Office, 2004). In an epidemiological study, Liu (2003) also found that consumption of fruits, vegetables and whole grains is associated with reduced risk of diabetes. The California Children's Healthy Eating and Exercise Practices Survey shows that on average, children age 9-11 consumed 3.2 servings of fruits and vegetables on a typical school day (Keihner, Garbolino \& Hudes, 2004). This consumption rate is below the recommended level needed to reap all the positive benefits found in fruits and vegetables such as fiber, vitamins and minerals.

\section{Physical Activity}

The American Heart Association suggests that prevention and intervention for overweight children and adolescents have a combined focus on diet and physical activity (Williams et al., 2002). McMurray and colleagues studied 1,140 subjects aged 11 to 14 years to assess the effects of increasing the aerobic components of the school's physical activity program and improving the knowledge about weight control and blood pressure (McMurray, Harrell \& Bangdiwala, 2002). These researchers found that an exercise program for youth could have a beneficial effect on blood pressure, independent of body weight loss. However, there has been little research examining associations among acanthosis nigricans and dietary and physical activity patterns in children.

\section{Study and Methods}

The purpose of this study was to assess the prevalence of overweight, hypertension and acanthosis nigricans among students at Four Winds Native American Charter School, and to investigate the associations among overweight, blood pressure, AN, fruit/vegetable consumption and physical activity. This was a cross-sectional descriptive study. We hypothesized that there would be a significantly lower prevalence of overweight, acanthosis nigricans, and hypertension among children with higher consumption of fruits and vegetables and higher physical activity levels.

\section{Participants}

During the spring of 2004, all students at the school were invited to participate in the study. Positive parental consent and child assent were criteria for inclusion. Students were free to withdraw from the study at any time. Human subjects approval was obtained from the California State University, Chico Human Subjects Review Committee.

\section{Data Collection}

Information regarding diet and physical activity behaviors and attitudes was self reported on a two-page questionnaire with four sections. The first section of the questionnaire addressed demographics of age, gender, grade level, and ethnicity. The second section involved questions 
regarding dietary habits and perceived physical activity patterns. The third section consisted of self-reports of soft drink, fruit, vegetable, and fast food consumption, asking students to rank (0-5) and respond to Likert statements for these items. The final part of the questionnaire included anthropometric, blood pressure and acanthosis screening data, collected directly by the researchers. The questionnaire was validated for content and face validity, ethnic sensitivity, and age appropriateness by CSU Chico faculty and Four Winds School staff members.

Data was collected at Four Winds Native American Charter School which has a student population of 104 individuals in kindergarten through 9th grades. Fifteen students were absent during the times of assessment, two did not have positive parental consent forms, and one chose not to participate. This resulted in 86 study participants.

Subjects completed the questionnaire regarding demographics, dietary and physical activity patterns in their respective classrooms during regular class time. A teacher and a researcher were present to assist students with questions or concerns about the survey. In addition, students in kindergarten through third grade were individually read the two statements: "I eat fruits and vegetables everyday" and "I am physically active everyday," to which students chose responses of yes, sometimes, or no. After completion of the questionnaire, students exited the classroom in small groups to participate in the anthropometric, BP, and AN measurements for the study in the screening room.

Height was recorded in inches to the nearest quarter inch via a standiometer and weight in pounds to the nearest half pound via a Healthometer Professional scale, model 1540. BMI was calculated using standard procedures $\left(\mathrm{kg} / \mathrm{m}^{2}\right)$; BMI-for-age percentiles of each participant were determined by using Center for Disease Control growth charts (Kumarski, Ogden \& Grummer-Strawn, 2000). Trained researchers screened each student for the presence or absence of AN by visual inspection of the neck. All students were screened for blood pressure by trained researchers using a standard sphygmomanometer, appropriate cuff size, and standard procedures (National Kidney Foundation, 2005). Prior to screening, students were asked to remain seated for five minutes to normalize heart rate and blood pressure.

Blood pressure guidelines issued by the National Heart, Lung, and Blood Institute (NHLBI) and the National High Blood Pressure Education Program define blood pressure for children in percentiles, accounting for height, sex, and age. The updated blood pressure tables are based on 1999-2000 National Health and Examination data and include the 50th, 90th, 95th, and 99th percentiles (NHLBI, 2004). The 99th percentile was added to allow more accuracy in the staging of hypertension, which begins at the 95th percentile. According to American Heart Association guidelines, blood pressure must be measured on three or more distinct occasions to confirm a diagnosis of pre-hypertension or hypertension. Hypertension in children is defined as average systolic blood pressure (SBP) and diastolic blood pressure (DBP) that exceeds the 95th percentile for gender, age and height. The pre-hypertensive category includes children with blood pressure values between the 85th and 95th percentile for gender, age and height (NCHS, 2003). Participants were classified into normal, pre-hypertensive, and hypertensive categories $\quad(<84.9$ th $\%, \quad 85-95$ th $\%,>95$ th $\%$, respectively). Students classified in the prehypertensive and hypertensive categories had their blood pressure measured for a second time to confirm the categorization.

\section{Statistical Analyses}

Data were analyzed using the Statistical Package for the Social Sciences (SPSS version 12, 2002). Descriptive statistics included counts, means, ranges, and standard deviations. T-tests and analysis of variance were performed to compare differences in BMI, blood pressure, diet, physical activity levels, and the prevalence of AN between subjects with high fruit/vegetable consumption and physical activity versus subjects with lower levels. Linear regression was utilized to observe associations between blood pressure, BMI, physical activity and fruit/vegetable responses. Chi-square was used to evaluate differences in rates of: $\mathrm{AN}$ by $\mathrm{BMI}$ 
group; BMI group by F/V intake; BMI group by level of physical activity; and blood pressure groups by fruit and vegetable responses. Statistical significance was determined at the $\mathrm{p}=.05$ level.

\section{Results}

Demographic information for students at Four Winds School is summarized in Table 1. Seventy-two percent of the students were American Indian $(n=62)$, making up the majority of participants. The non-American Indian group $(n=24)$ consisted of $14 \%$ White $(n=12), 12 \%$ Hispanic $(n=10)$, and $2 \%$ African American $(n=2)$. The average age among participants was $10.2 \pm 3.2$ years and $60 \%$ were male. Forty-eight percent were $\geq 85$ th percentile BMI for their age $(n=51)$. Fifty-three percent of the Native American study participants were overweight or at-risk-for-overweight (BMI $\geq 85$ th percentile), while $35 \%$ of the non-Native American participants were overweight or at-risk-foroverweight. The prevalence of AN was $14 \%$ $(\mathrm{n}=11), 11 \%$ positive for AN only $(\mathrm{n}=9)$. Thirtytwo percent of the total sample $(n=27)$ were classified as either pre-hypertensive $(15 \%)$ or hypertensive $(17 \%)$ based on a single blood pressure reading. This percentage was consistent at $32 \%$ for both the American Indian and nonAmerican Indian students in this sample. Nine of the 20 students $(45 \%)$ who were classified a prehypertensive or hypertensive from the first reading maintained elevated blood pressure with the second reading.

At $60 \%$ vs. $35 \%$ respectively, the percentage of individuals either overweight or at-risk-foroverweight was significantly higher $(p=.02)$ among fourth through ninth graders compared with students in kindergarten through third grades (see Figure 1).

Table 1

Descriptive Statistics of Anthropometric and Health Indices for Students at Four Winds School (N=85)

\begin{tabular}{|c|c|c|}
\hline Anthropometric and Health Indices & N & Percent \\
\hline Age & & \\
\hline 5-8 years & 40 & 47 \\
\hline 9-15 years & 45 & 53 \\
\hline Gender & & \\
\hline Male & 32 & 60 \\
\hline Female & & 40 \\
\hline Ethnicity & 62 & 72 \\
\hline American Indian & 24 & 28 \\
\hline Non-American Indian & & \\
\hline Body Mass Index (BMI)(kg/m $\left.{ }^{2}\right)$ & 44 & 52 \\
\hline$<85$ th Percentile & 12 & 14 \\
\hline 85-94.9th Percentile & 29 & 34 \\
\hline$\geq 95$ th Percentile & & \\
\hline Presence of Acanthosis nigricans & 11 & 14 \\
\hline Positive & 70 & 86 \\
\hline Negative & & \\
\hline Blood Pressure Class & 57 & 68 \\
\hline$<90$ th Percentile & 12 & 14 \\
\hline 90-94.9th Percentile & 15 & 18 \\
\hline$\geq 95$ th Percentile & & \\
\hline
\end{tabular}


Grades K-3 (N=40)

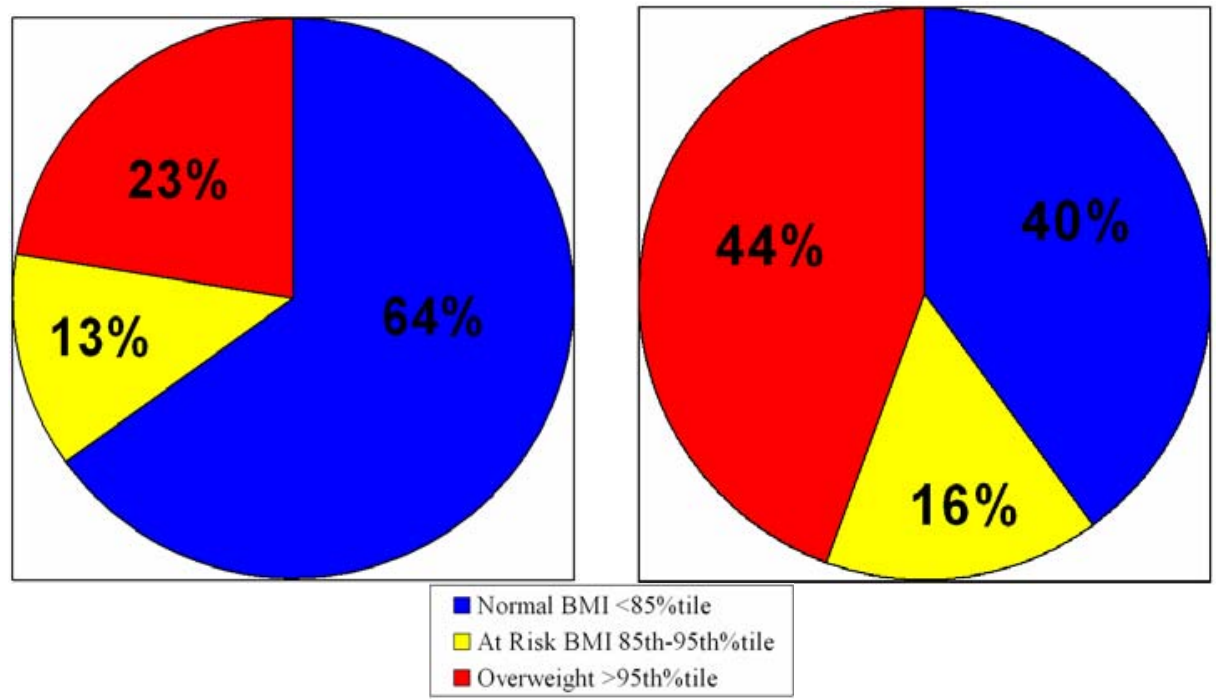

Figure 1

Rate of overweight and grade level $(\mathrm{N}=85)$
Mean systolic and diastolic blood pressures from the first reading differed among BMI groups such that students who were overweight $(n=29)$ had higher mean systolic $(117 \pm 23$ vs. $106 \pm 14$, $\mathrm{p}=.01)$ and diastolic blood pressures $(70 \pm 13 \mathrm{vs}$. $64 \pm 9, \mathrm{p}=.02$ ) compared to those in the normal BMI group $(n=55)$. Mean blood pressure readings for students in the at-risk for overweight category were not significantly different from either normal weight or overweight students.

For the first $\mathrm{BP}$ reading, the mean BMI for the students with a systolic blood pressure (SBP) equal to or higher than $120 \mathrm{~mm} \mathrm{Hg}$ was $27.3 \pm$ 7.0. This was compared to the mean BMI of $20.0 \pm 4.9$ for those with a SBP less than 120 . This is a significant difference of 7.4 BMI units $(\mathrm{p}=.001)$.

Seventy-four percent or 20 of the 27 students classified in the hypertensive category were available for a second reading. Some students failed to be re-screened due to school absenteeism or conflicting school activities. Nine students (45\%) of this group of 20 persisted with HTN based on the results of the second reading. For the second BP reading, there was a mean difference of 5.5 BMI units between students with a systolic BP more than 120 $\mathrm{mmHg}(29.9 \pm 7.8)$ vs. those with a systolic BP less than $120 \mathrm{mmHg}(24.4 \pm 3.8, \mathrm{p}=.053)$.

Students agreeing with the statement that they usually eat at least five fruit and vegetable servings per day $(n=68)$ had a significantly lower BMI $(20.6 \pm 6.0)$ compared with those students $(n=16)$ who did not agree with this statement $(\mathrm{BMI}=26.0 \pm 5.6, \mathrm{p}=.002)$. In support of this finding, reported fruit and vegetable intake differed by BMI group such that overweight students consumed approximately one serving less per day of each $(2.6 \pm 1.5$ fruits and $2.2 \pm 1.5$ vegetables) compared to those who were not overweight $(3.4 \pm 1.5$ fruits and $3.1 \pm$ 1.5 vegetables).

Attitude toward daily fruit and vegetable intake was associated with mean systolic blood pressure reading such that students who strongly agreed $(n=19)$ with the statement that they usually eat at least five fruits and vegetables per day had a significantly lower mean systolic BP $(110 \pm 17 \mathrm{mmHg})$ vs. students who did not 
strongly agree with this statement $(n=26,126 \pm$ $17 \mathrm{mmHg}, \mathrm{p}=.007$ ).

At $33 \%$, the rate of elevated BP $(>$ 85th percentile) was the same for students positive for $\mathrm{AN}$ as it was for the entire sample. AN was positively associated with BMI $(\mathrm{p}=.001)$ such that as BMI increased, the prevalence of $\mathrm{AN}$ also increased. The prevalence of AN was $37 \%$ among students with a BMI greater than the 85 th percentile vs. $14 \%$ for the sample overall. There were no positive AN cases among students who had a BMI less than the 85th \%tile. Of the 11 students who were positive for AN, only 54\% agreed with the Likert statement that they usually eat greater than or equal to five fruits and vegetables a day vs. $84 \%$ for the 69 students without AN.

Reported soda intake was negatively correlated with a usual consumption pattern of five or more fruits and vegetables a day $(\mathrm{r}=-.396, \mathrm{p}=.03)$ and positively correlated with systolic BP, although the latter relationship did not reach statistical significance $(4=.206, \mathrm{p}=.09)$. The association between systolic BP and time spent in sedentary behavior is noteworthy at a $\mathrm{p}$ value of .06 $(\mathrm{r}=.235)$ such that as time spent in sedentary activity increased, systolic blood pressure also increased.

Linear regression results indicate that BMI and attitude toward the importance of fruit and vegetable consumption are independent predictors of systolic BP $(\mathrm{p}=.001)$ such that systolic BP increases with a higher BMI and a less positive attitude toward fruit and vegetable consumption.

\section{Discussion}

Fifty-three percent of the Native American study participants were overweight or at-risk-foroverweight (BMI $\geq 85$ th percentile) compared to $35 \%$ of the non-Native American participants. This rate of $53 \%$ is notably higher than the $30 \%$ rate for all U.S. children reported by Freedman and colleagues (1999) and is comparable to the $52 \%$ reported by Soddart and colleagues (2002) and the $63 \%$ reported by Smith and Rinderknecht (2003) for Native American school children. The higher rate reported by
Smith and Rinderknecht may be partially explained by the inclusion of high school students in their sample vs. the K-9 student sample in the present study.

The authors found a disturbing trend of overweight among students as they increased in age. Among the students in the fourth to ninth grades, the percentage of overweight and at-riskfor-overweight students exceeded that of students within the normal weight category, $60 \%$ vs. $40 \%$, respectively. This $60 \%$ rate for the fourth to ninth grade students is notably higher than the $30 \%$ reported by the CDC based on the National Health and Examination Study of 1999-2000 (NCHS, 2003). Looking at the overweight category ( $\geq 95$ th percentile) alone, the percent of children in the fourth to ninthgrade group was nearly twice as high as the kindergarten to third-grade group (44\% vs. 23\%). Comparably, Smith and Rinderknecht (2003) found the prevalence of overweight increased from $38 \%$ among five to ten year olds to $45 \%$ among $11-18$ year olds. In addition to the increased rate of overweight as children get older, findings from the current study support previous research that overweight and related risk factors are higher among American Indians (Story et al., 1999).

Blood pressure was found to be associated with BMI in the present study such that students who were overweight had higher mean systolic and diastolic blood pressures compared to those who were not overweight. This finding is consistent with findings by Burke and colleagues (2004) among western Australian youth $(\mathrm{n}=1,066)$ and Sorof's (2004) finding that overweight schoolage children have a three-fold risk for developing hypertension compared to their normal weight peers.

Sorof (2004) found that cases of elevated blood pressure decreased by half after each screening. In agreement with this finding, the current study found that $45 \%$ of the participants maintained elevated blood pressure at the second reading.

The finding that mean BMI increased incrementally for normal, pre-hypertensive, and hypertensive groups is supportive of prior 
findings by Sorof (2004) showing that overweight school-aged children have a higher prevalence of hypertension. Regression results identifying BMI as an independent risk factor for elevated blood pressure are also in agreement with Sorof's findings. Based on these collective findings, it may be assumed that overweight is a risk factor for high blood pressure among youth (Muntner, He, Cutler, Wildman \& Whelton, 2004).

As expected, acanthosis nigricans was significantly associated with BMI such that all AN cases were found in students who were either at-risk-for-overweight or overweight. This is in agreement with the finding by Stoddart et al. (2002) that rates for AN for both at-risk-foroverweight and overweight students were four times higher than the AN rate for normal weight students.

There was a mean difference of one serving per day of both fruit and vegetable consumption between students above vs. below the 85 th $\%$ tile BMI-for-age with a higher reported mean rate of consumption for normal weight students. Positive attitudes about fruit and vegetable consumption were related to blood pressure; as the perceived importance of fruit and vegetable consumption increased, the prevalence of elevated blood pressure decreased. There was a $16 \mathrm{mmHg}$ difference in mean systolic blood pressure between students who strongly agreed that it is important to eat five fruits and vegetables a day and those who agreed or were neutral in their attitude. However, reported consumption of fruits and vegetables did not appear to be associated with blood pressure in this study. Comparative findings in the literature are not available.

No significant associations were observed between soda consumption or physical activity and our dependent variables of BMI, AN, and blood pressure. Soda consumption did not differ by BMI group. However, soda intake was negatively correlated with usual consumption of fruits and vegetables. The mean intake of two servings of soda a day, as reported by these students, is noteworthy.
All positive AN cases and $78 \%$ of those students categorized as either pre-hypertensive or hypertensive were above the 85th \%tile BMIfor-age, indicating that overweight and at-riskfor-overweight students should be screened for weight-related risk factors for chronic disease.

\section{Limitations}

Limitations to these findings are that dietary information was self-reported and the data collection instrument was brief. Instruments were designed to be short in light of the students' attention span and time constraints. Hence, diet and physical activity patterns were not fully explored. Because the questionnaire was conducted in a group setting, the answers may have been influenced by peer pressure, despite the presence of researchers and teachers.

The small sample size is a major limitation. All investigations of relationships between diet and physical activity and the dependant variables of BMI, AN and BP were based on 45 fourththrough-ninth-grade students out of the total sample of $86 \mathrm{~K}-9$ th grade students.

The blood pressure data reported in this study were based on a single measure. According to the current guidelines for pre-hypertension and hypertension in children, participants should be screened three or more times prior to being diagnosed with pre-hypertension or hypertension (National Heart, Lung, and Blood Institute, 2004). Therefore, the prevalence rates of prehypertension and hypertension in this study are overestimations.

\section{Conclusions}

There are several conclusions for this study: (1) The high rates of overweight, AN and elevated blood pressure among these school children indicate a need for nutrition education and physical activity promotion; (2) Nutrition educators, school staff, and parents should focus on supporting positive attitudes towards fruit and vegetable intake among youth, as intake appears to be associated with decreased risk for elevated blood pressure; (3) Students with three of the following risk factors for chronic disease - hypertension, AN, and overweight - should receive appropriate intervention; and (4) Future 
studies with larger sample sizes are needed to further explore associations among diet, physical activity, BMI, acanthosis nigricans, and blood pressure in children.

\section{Implications}

It is critically important to introduce healthy eating habits to children early, when impressions are beginning to form. Children as young as seven years of age are able to grasp concrete concepts about foods and their health benefits. Research indicates that children who are exposed to healthy food patterns early in their lives are able to explain their consumption of healthier foods at a later date (Rasanen et al., 2004). The inclusion of parents in the active learning process increases the likelihood that children will learn and recognize healthy food choices. Programs such as LEAP for Preschoolers and LEAP for Families, (Monastra et al., 2005), and California's 5-a-Day-Power Play! Campaign for school aged children have been instrumental in promoting good health through the adoption of healthy eating and activity patterns with a focus on increased fruit and vegetable consumption.
California State University, Chico has developed a Center for Nutrition and Activity Promotion, directed by this study's first author. The Center partners nutrition experts, university students, county public health agencies, and public schools to offer prevention programs against overweight, inactivity, hypertension and diabetes. The Center encompasses seven different programs, including the 5-a-Day Power Play! Campaign for the Sierra Cascade region of California, the OPT for Fit Kids program, and the Sierra Cascade Nutrition and Activity Consortium. The latter focuses on lowincome children, and is funded by the United States Department of Agriculture and the California Nutrition Network, under the auspices of the Department of Health Services. These programs attempt to influence a shift to more healthy eating habits and increased physical activity among children. They do so by involving many players in the child's world parents, teachers, health professionals, and university students.

\section{References}

Arslanian, S. A. (2000). Type 2 diabetes mellitus in children: Pathophysiology and risk factors. Journal of Pediatric Endocrinology Metabolism, 13, 1385-94.

Burke, V., Beilin, L., Dunbar, D., and Kevan, M. (2004). Associations between blood pressure and overweight defined by new standards for body mass index in childhood. Preventive Medicine, 38, 558-564.

Bursac, Z., and Campbell, J. E. (2003). From risky behavior to chronic outcomes. Current status and healthy people: 2010 goals for American Indians in Oklahoma. Journal of the Oklahoma State Medical Association, 96(12), 569-73.

Freedman, D. S., Dietz, W. H., Srinivansan, S. R., and Berenson, G. S. (1999). The relation of overweight to cardiovascular risk factors among children and adolescents: The Bogalusa Heart Study. Pediatrics, 103, 1175-1182.

Gahagan, S., and Silverstein, J. (2003). Prevention and treatment of Type 2 diabetes mellitus in children, with special emphasis on American Indian and Alaska Native children. Pediatrics, 112, 4, e328.

Gray, A., and Smith, C. (2003). Fitness, dietary intake, and body mass index in urban Native American youth. Journal of the American Dietetic Association, 103, 1187-1191.

Keihner, A. J., Garbolino, T., and Hudes, M. (2004). Findings from the 1999 California healthy eating and exercise practices survey: Intervention implications and campaign evaluation. Sacramento CA: California Department of Health Services.

Kucmarski, R. J., Ogden, C. L., and Grummer-Strawn, L. M. (2000). CDC growth charts: United States. Advanced Data, 314, 1-27.

Liu, R. H. (2003). Protective role of phytochemicals in whole foods: Implications for chronic disease prevention. Applied Biotechnology, Food Science and Policy, 1(1), 39-46. 
McMurray, R. G., Harrell, J. S., Bangdiwala, S. I., Bradley, C. B., Deng, S., and Levine, A. (2002). A school-based intervention can reduce body fat and blood pressure in young adolescents. Journal of Adolescent Health, 31(2), 125-32.

Monostra, M. A., Bordin, J., Wolff, C. B. (2005). LEAP works! Outcomes of a family based nutrition education and physical activity promotion program. Californian Journal of Health Promotion, 3(3), 43-60.

Muntner, P., He, J., Cutler, J. A., Wildman, R. P., and Whelton, P. K. (2004). Trends in blood pressure among children and adolescents. Journal of the American Medical Association, 291, 2107-2113.

Nader, P. R., O'Brien, M., Houts, R. Bradley, R., Belsky, J., Crosnoe, R. et al. (2006). Identifying risk for obesity in early childhood. Pediatrics, 118, e594-e601.

National Center for Health Statistics (NCHS). (2003). National health and nutrition examination survey (NHANES) 1999-2000. Retrieved December 17, 2006, from http://www.cdc.gov/nchs/nhanes.htm

National Heart, Lung, and Blood Institute (NHLBI). (2004). The fourth report on the diagnosis, evaluation, and treatment of high blood pressure in children and adolescents. Pediatrics, 114, ii.

National Kidney Foundation. (2002). K/DOQI clinical practice guidelines on hypertension and antihypertensive agents in chronic kidney disease. Guideline 13: Special considerations in children. Retrieved December 17, 2006, from http://www.kidney.org/professionals/kdoqi/guidelines bp/guide 13.htm

National Institutes of Health. (2002). Childhood obesity on the rise. Word on health. Retrieved December 17, 2006, from http://www.nih.gov/news/WordonHealth/jun2002/childhoodobesity.htm

National Institutes of Health. (2006). Overweight in early childhood increases chances for obesity at age 12. NIH News. Retrieved December 17, 2006, from http://www.nichd.nih.gov/news/releases/obesity risk early childhood.cfm

Patrick, K., Norman, G., Calfas, K., Sallis, J., Zabinski, M., Rupp, J., and Cella, J. (2004). Diet, physical activity and sedentary behaviors as risk factors for overweight in adolescence. Archives of Pediatric Medicine, 158, 385-390.

Rasanen, M., Keskinen, S., Niinikoski, H., Simmell, O., Ronnemaa, T., Helenius, H., and Viikari, J. (2004). Impact of nutrition counseling on nutrition knowledge and nutritent intake of 7-9-yearold children in an atherosclerosis prevention project. European Journal of Clinical Nutrition, 58, 162-172.

Scheinfield, N. S. (2004). Obesity and dermatology. Clinics in Dermatology, 22, 303-309.

Smith, C., and Rinderknecht, K. (2003). Obesity correlates with increased blood pressure in urban Native American youth. American Journal of Human Biology, 15, 78-90.

Sorof, J. (2004). Overweight, ethnicity, and the prevalence of hypertension in school-aged children. Pediatrics, 113, 475-482.

Sorof, J., and Daniels, S. (2002). Obesity hypertension in children: A problem of epidemic proportions. Hypertension, 40, 441.

Steinberger, J., and Daniels, S. R. (2003). Obesity, insulin resistance, diabetes, and cardiovascular risk in children: An American Heart Association scientific statement from the atherosclerosis, hypertension, and obesity in the young committee (Council on Cardiovascular Disease in the Young) and the diabetes committee (Council on Nutrition, Physical Activity, and Metabolism). Circulation, 107, 1448-1453.

Stoddart, M., Blevins, K., Lee, E., Wang, W., and Blackett, P. (2002). Association of acanthosis nigricans with hyperinsulemia compared with other selected risk factors for type 2 diabetes in Cherokee Indians. Diabetes Care, 25, 1009-1014.

St-Onge, M. P., Keller, K., and Heymsfield, S. B. (2003). Changes in childhood food consumption patterns: a cause for concern in light of increasing body weights. American Journal of Clinical Nutrition, 78, 1068-1073. 
Story, M., Evans, M., Fabsitz, R., Clay, T., Rock, B., and Broussard, B. (1999). The epidemic of obesity in American Indian communities and the need for childhood obesity-prevention programs. American Journal of Clinical Nutrition, 69, 747S-754S.

Story, M., Stevens, J., Himes, J., Stone, E., Rock, B. H., Ethelbah, B., Davis, S. (2003). Obesity in American Indian children: Prevalence, consequences, and prevention. Preventive Medicine, 37, S3-S12.

Story, M., Strauss, K., Zeprhier, E., and Broussard, B. (1998). Nutritional concerns in American Indian and Alaska Native children: Transitions and future directions. Journal of the American Dietetic Association, 98, 170-176.

Stuart, C., Smith, M., Gilkison, C., Shaheb, S., and Stahn, R. (1994). Acanthosis nigricans among Native Americans: An indicator of high diabetes risk. American Journal of Public Health, 11, 18391842.

United States General Accounting Office Report to Congressional Requesters. (2002, July). Fruit and Vegetables: Enhanced Federal Efforts to Increase Consumption Could Yield Health Benefits for Americans. Retrieved December 17, 2006, from http://www.gao.gov/new.items/d02657.pdf

Williams, C.L., Hayman, L.L., Daniels, S.R., Robinson, T.N., Steinberger, J., Paridon, S., and Bazzarre, T. (2002). Cardiovascular health in childhood: A statement for health professionals from the committee on atherosclerosis, hypertension, and obesity in the young (AHOY) of the council on cardiovascular disease in the young, American Heart Association. Circulation, 106, 143-160.

Yamazaki, H., Ito, S., and Yoshida, H. (2003). Acanthosis nigricans is a reliable cutaneous marker of insulin resistance in obese Japanese children. Pediatrics International, 45, 701-705.

\section{Acknowledgements}

The authors would like to thank the students and staff at Four Winds Native American Charter School, the California Nutrition Network, and the California Department of Health Services.

\section{$\underline{\text { Author Information }}$}

Cindy Wolff, PhD, MPA, RD, Professor

Nutrition and Food Sciences Program

Director, Center for Nutrition and Activity Promotion

California State University, Chico

Ph.: 530-898-5288

E-Mail: cwolff@csuchico.edu

Sabrina Hoang

Center for Nutrition and Activity Promotion

California State University, Chico

Diana Flannery, PhD, Professor

Department of Health and Community Services

California State University, Chico

Laurie Wermuth, PhD

Department of Sociology

California State University, Chico

* corresponding author 